\title{
Biological underpinnings of trauma and post-traumatic stress disorder: focusing on genetics and epigenetics
}

\begin{abstract}
Certain individuals are more susceptible to stress and trauma, as well as the physical and mental health consequences following such exposure, including risk for posttraumatic stress disorder (PTSD). This differing vulnerability is likely to be influenced by genetic predisposition and specific characteristics of the stress itself (nature, intensity and duration), as well as epigenetic mechanisms. In this review we provide an overview of research findings in this field. We highlight some of the key genetic risk factors identified for PTSD, and the evidence that epigenetic processes might play a role in the biological response to trauma, as well as being potential biomarkers of PTSD risk. We also discuss important considerations for future research in this area.
\end{abstract}

First draft submitted: 8 July 2016; Accepted for publication: 22 August 2016; Published online: 30 September 2016

Keywords: biomarkers $\bullet$ DNA methylation $\bullet$ early life $\bullet$ epigenetics $\bullet$ genetics $\bullet$ humans - post-traumatic stress disorder $\bullet$ stress $\bullet$ trauma

The majority of individuals will encounter some form of trauma or severe stress over their lifetime, however, most have the capacity to recover from such events without any long term health consequences [1]. Post-traumatic stress disorder (PTSD) is a chronic and highly debilitating psychiatric disorder which develops in a small number of people following exposure to a single traumatic event or multiple/chronic exposures over time [2]. This includes through direct involvement of the individual, as well as witnessing or hearing of the event occurring to a close friend or family member. PTSD is highly heterogeneous and can manifest in different ways, with 20 clinical symptoms as defined in the Diagnostic and Statistical Manual of Mental Disorders version 5 [3]. The core symptoms are re-experiencing (e.g., flashbacks, intrusive memories and nightmares), avoidance behaviors, negative alteration in cognitions and mood, and hyperarousal [3]. The prevalence rates of PTSD range from about $2-8 \%[4,5]$, and it is more common in those experiencing certain types of trauma, such as having a child with a serious illness [6] and severe trauma which may pose a threat to life (particularly violence and military combat, and to a lesser extent severe accidents and disasters) [7]. However, even for individuals experiencing the same trauma, there is considerable interindividual variability in their resilience and risk of PTSD, most likely due to underlying differences in biological processes, possibly genetic or epigenetically driven.

Here, we aim to provide a brief overview of the role of genetic and epigenetics in trauma, by highlighting some of the main findings to date. Recommendations for future research which will help advance our knowledge in this field are also discussed. While we acknowledge the essential contribution of animal studies, this review will focus predominantly on findings in humans. The majority of studies have investigated PTSD due to its direct etiological link with trauma, providing a model for gene and environment interactions, including those mediated by epigenetics.
Joanne Ryan*,1,3,4, Isabelle Chaudieu $^{3}$, Marie-Laure Ancelin ${ }^{\ddagger, 3}$ \& Richard Saffery ${ }^{\ddagger 1,2}$ ${ }^{1}$ Cancer \& Disease Epigenetics Group, Murdoch Children's Research Institute, Royal Childrens Hospital, Parkville 3052, Victoria, Australia

2Department of Paediatrics, The University of Melbourne, Parkville 3052, Victoria, Australia

Inserm, U1061, University of Montpellier, Montpellier F-34093, France ${ }^{4}$ Department of Epidemiology \& Preventive Medicine, School of Public Health \& Preventive Medicine, Monash University, Prahran 3004, Australia *Author for correspondence: Tel.: +61399366 621 Fax: +61393481391 joanne.ryan@mcri.edu.au ${ }^{\ddagger}$ Authors contributed equally 


\section{Heritability of experiencing trauma \& PTSD} Family linkage studies which investigate patterns of diseases within families provide good evidence for the heritability of PTSD. Among Holocaust survivors for example, those with PTSD were much more likely to have children who also developed PTSD following exposure to trauma [8], although this estimate is likely inflated due to the shared family environment. Twin studies have been invaluable in this context, by comparing the degree of similarity in traits between monozygotic (MZ) and dizygotic (DZ) twins, enabling the genetic contribution of a disorder to be estimated. Such studies of PTSD indicate a relatively high heritability explaining up to $45 \%$ of the variability in risk [9], with ranges from 13 to $69 \%$ when individual PTSD symptoms are considered.

The persisting and unique complication in estimating the underlying genetic contribution of PTSD, however, is that the risk is directly tied to the occurrence of a traumatic event and cannot be estimated in individuals who have not been exposed. Furthermore, an individual's likelihood of experiencing trauma, in particular certain types of trauma, may also have a genetic component. Studies of male MZ twin pairs have found a twofold higher concordance in volunteering for and serving in the military [10], as well as a significantly higher intrapair correlation in selfreported combat experiences [10,11]. In a study of 2591 adult twins and their siblings, additive genetic factors were estimated to account for $60 \%$ of the variance of high-risk trauma (e.g., childhood sexual and physical abuse, neglect), while for other traumas this was lower, at $47 \%$ [9]. By comparing the intrapair correlations of exposure between $222 \mathrm{MZ}(0.53)$ and $184 \mathrm{DZ}$ twins (0.23), Stein et al. also found a moderate genetic component to the risk of exposure for some assaultive traumas (i.e., robbery and sexual assault), but not for motor vehicle accidents or natural disasters (intrapair correlation 0.35 and 0.26 for $\mathrm{MZ}$ and DZ twins, respectively) [12].

A likely explanation for the high heritability of experiencing specific traumas may relate to personality traits that can influence behavior and lifestyle choices, including risk taking behaviors. Indeed, antisocial personality traits, self-harming behavior and substance misuse have been shown to predict the risk of violent assaultive trauma, and these are partly mediated by genetic factors [13]. Few studies, however, have yet attempted to identify the individual genes involved in influencing risk. Furthermore, it remains unclear to what extent genetic risk factors for trauma and PTSD overlap. A Norwegian study of 2794 adults determined that only one fifth of the familial liability (genetic and common environmental factors) of PTSD symptoms overlapped with the liability for trauma exposure [14]. However, another study reported a very high correlation between genetic risk factors for trauma and PTSD [9], highlighting the importance of controlling for the risk of trauma in genetic association studies of PTSD.

\section{Genetic risk variants for PTSD}

The majority of studies investigating genetic risk factors for PTSD have been candidate gene-association studies, where genes were selected based on their known or perceived involvement in the etiology, pathology or neurobiology of the disease. Functional variants within these genes are often targeted. Currently more than 25 genes have been examined and some of the main findings are summarized in Table 1.

The early genetic association studies targeted dopaminergic signaling, given the long-established role of dopamine in the stress response [58]. Dopamine is released following stress [59] and dopamine levels have been directly correlated with the magnitude of the cortisol response to stress [60]. A number of studies have investigated SNPs in the dopamine receptor DRD2 or a specific variant (rs1800497) in the closely positioned ANKK1 gene which can regulate DRD2 [61]. Almost all studies involved Caucasian military men exposed to combat, however, the findings have been variable. In regards to $r$ 1800497, a few studies report that the $\mathrm{T}$ allele is associated with increased PTSD risk $[17,18]$. However, other larger studies have found no association [19]. Other SNPs investigated have varied across studies [15,20]. A more recent and larger study of men and women exposed to a range of traumas (651 PTSD cases, 1098 controls), reported a significant association with a specific SNP (rs12364283) in DRD2 [16]. However, this was a case-control study of heroin dependence, and the associations identified were predominantly limited to amphetamine-dependent individuals. More consistent findings have been reported for the dopamine transporter DAT1, where the shorter variable number tandem repeat increased the risk of PTSD, even in those exposed to very different traumas (i.e., natural disasters, war and violence) [21,22].

Dysfunction of serotonergic signaling is thought to play a role in the pathophysiology of PTSD [62], and some treatments for PTSD target this pathway, with mixed success [63]. The transporter gene 5-HTT, essential for neurotransmitter signaling, has been extensively studied, with most studies focusing on a functional variant that affects gene transcription [64]. The 5-HTTLPR linked polymorphism consists of a 44-bp insertion/deletion and the short (' $S$ ') compared with the long ('L') allele leads to reduced gene transcription. Several, but not all studies [23,24], have reported that 
5-HTTLPR (with or without consideration of the proximal rs25531 variant), influences the risk of PTSD [25]. The $S$ allele has been associated with an increased risk of PTSD following exposure to natural disasters, civilian war, physical and childhood traumas, and in different ethnic populations. On the other hand, a couple of studies have reported reversed associations, in that individuals homozygous for the $S$ allele actually had a reduced PTSD risk $[65,66]$. These conflicting findings may be explained by the differential susceptibility hypothesis [67], which posits that certain genetic variants are more responsive to the environment, being risk factors under certain conditions but conferring resilience in others. In support of this, a study of 590 individuals found that the $S$ allele increased the risk of PTSD following a natural disaster, however, only for individuals in high-risk environments [26]. For individuals living in areas with low unemployment and crime rates, the $S$ allele was associated with a decreased risk [26]. Other studies have also shown that the $S$ allele is a risk factor for PTSD only in the absence of social support [27], in individuals having experienced both a childhood trauma and a later event in adulthood [28], or in response to severe traumas but not milder events [29].

Genes of the HPA-axis are obvious candidates for studies of PTSD given that this axis is activated in response to stress and influences a broad range of biological processes (Figure 1). A study of CRHR1 identified variants that were associated with PTSD symptoms in adults following a hurricane exposure. One, rs12938031, also predicted PTSD diagnosis [32], but this has not been replicated [33]. Two complementary studies found that severe childhood trauma interacts with genetic variation in FKBP5 to increase the risk of PTSD in adults. In the Grady Trauma Project, four highly linked SNPs (rs9296158, rs3800373, rs 1360780, rs9470080) interacted with the severity of childhood abuse to predict risk of PTSD symptoms in adulthood [39]. A subsequent study reported that three of these four variants were independently associated with the risk of PTSD in a similar ethnic group (African-Americans), but there were no significant associations in a non-Hispanic white population [40]. These ethnic-specific findings may be explained by differences in genotype frequencies, including a higher frequency of risk variants in African-Americans and varying degrees of linkage disequilibrium with other potential risk alleles. Furthermore, environment specific factors may also contribute to risk. Interestingly in this study, childhood adversity was a stronger risk factor for PTSD in European rather than African-Americans [40]. One of these genetic variants ( $r$ 9470080) also interacted with childhood adversity to increase PTSD risk, thus replicating the earlier findings [39]. The $r s 1360780$ genetic variant may also influence the effectiveness of psychotherapy in PTSD patients [68]. A single PTSD study found no association with variants in the glucocorticoid receptor gene $N R 3 C 1$, despite it being the most extensively studied gene in epigenetic analysis (discussed later) [34].

The neuropeptide pituitary adenylate cyclaseactivating polypeptide and its PAC1 receptor have been shown to be unregulated following chronic stress and they in turn can activate $C R H$ transcription [69,70]. The genes coding for pituitary adenylate cyclase-activating polypeptide and PCA1 (ADCYAP1 and ADCYAPIR1, respectively) have been investigated in a highly traumatized African-American population, comparing PTSD cases and controls matched on type of trauma [42]. The rs2267735 SNP of ADCYAP1R1 was associated with diagnosis of PTSD and PTSD symptoms in females only [42] and subsequently replicated [43]. ADCYAP1R1 gene expression has been shown to be modulated by the female sex-hormone, estrogen [42], and rs2267735 is positioned in a putative estrogen response element, within the gene, possibly explaining the gender-specific associations. A Chinese study investigating this variant, reported no association with total PTSD symptoms, but it predicted the severity of specific symptoms in women who had lost a child in a natural disaster [44].

$B D N F$ is a neurotrophin that plays a key role in the formation, plasticity and integrity of neurons in brain circuits regulating emotion. Stress appears to regulate BDNF signaling [71], resulting in increased BDNF serum levels [69] which have also been observed in PTSD [72]. A variant of this gene, $r s 6265$, has been associated with the risk of PTSD in male war veterans [46] and therapy response in patients [47], as well as specific features of PTSD, such as fear conditioning. By contrast, earlier studies of civilian populations experiencing various types of other traumas reported no associations, even with compatible sample sizes [48].

Other candidate genes investigated include COMT, implicated in the metabolism of catecholamines [51]; PRKCA implicated in diverse signaling processes [55,56], $C N R 1$, which is involved in dopamine regulation and stress [50] and $A P O E$ thought to influence stress reactivity [45]. $C R P$ is a proinflammatory marker and increased circulating levels of this protein have been observed in individuals with PTSD. The variant $r s 1130864$ of this gene was associated with increased CRP serum levels, PTSD diagnosis and severity of PTSD symptoms [52]. A single SNP OPRL1 was associated with both PTSD symptoms and a self-reported history of childhood trauma [54], which supports the potential beneficial effect of opioid analgesia on PTSD [73]. However, there is currently insufficient evidence to clearly implicate any of these genes in PTSD. 
Table 1. Candidate genes investigated in genetic or epigenetic studies of post-traumatic stress disorder.

\begin{tabular}{|c|c|c|c|c|c|}
\hline \multirow[t]{2}{*}{ Pathway and gene } & \multicolumn{3}{|c|}{ Gene-association studies } & \multicolumn{2}{|c|}{ DNA methylation studies } \\
\hline & Symbol & Region & Risk of PTSD & Tissue and sites & Risk of PTSD ${ }^{+}$ \\
\hline \multicolumn{6}{|l|}{ Dopaminergic signaling } \\
\hline Dopamine receptor D2 & $D R D 2$ & Various SNPs & $\begin{array}{l}\text { Some } \\
\text { associations }[15,16]\end{array}$ & $\mathrm{NI}$ & \\
\hline $\begin{array}{l}\text { Ankyrin repeat } \\
\text { and kinase domain } \\
\text { containing } 1\end{array}$ & ANKK1 & rs1800497 & $\begin{array}{l}\uparrow \text { with T allele; others } \\
\text { no association [17-19] }\end{array}$ & $\mathrm{NI}$ & \\
\hline Dopamine receptor D4 & $D R D 4$ & Exon 3 VNTR & $\uparrow$ with $\mathrm{L}_{\text {allele }}^{\dagger}[20]$ & $\mathrm{NI}$ & \\
\hline Dopamine transporter & $\begin{array}{l}\text { DAT1; } \\
\text { SLC6A3 }\end{array}$ & VNTR in $3^{\prime}$ UTR & $\begin{array}{l}\uparrow \text { with nine } \\
\text { repeat }[21,22]\end{array}$ & $\begin{array}{l}\text { Blood, two loci } \\
\text { in promoter } \\
\text { (using HM27K } \\
\text { array data) }\end{array}$ & $\begin{array}{l}\text { No independent } \\
\text { association. Gene } \\
\times \text { methylation } \\
\text { interaction }[21]\end{array}$ \\
\hline \multicolumn{6}{|l|}{ Serotonin signaling } \\
\hline Serotonin transporter & $\begin{array}{l}\text { 5-HTT; } \\
\text { SLC6A4 }\end{array}$ & 5-HTTLPR, VNTR & $\begin{array}{l}\uparrow \text { risk with S allele } \\
\text { (predominantly) [23-29] }\end{array}$ & $\begin{array}{l}\text { Blood, two loci } \\
\text { in promoter } \\
\text { (using HM27K } \\
\text { array data) }\end{array}$ & $\begin{array}{l}\text { No independent } \\
\text { association. } \\
\text { Trauma-methylation } \\
\text { interaction }[30,31]\end{array}$ \\
\hline Serotonin receptor $2 \mathrm{~A}$ & HTR2A & rs6311 & $\uparrow$ with G allele ${ }^{\dagger}[24]$ & $\mathrm{NI}$ & \\
\hline \multicolumn{6}{|l|}{ HPA-axis signaling } \\
\hline $\begin{array}{l}\text { Corticotrophin-releasing } \\
\text { hormone receptor } 1\end{array}$ & CRHR1 & Various SNPs & $\begin{array}{l}\text { Some } \\
\text { associations }^{\dagger}[32,33]\end{array}$ & $\mathrm{NI}$ & \\
\hline Glucocorticoid receptor & NR3C1 & Various SNPs & No associations $^{\dagger}[34]$ & $\begin{array}{l}\text { Various, regions } \\
\text { in exon one } \\
\text { promoter }\end{array}$ & $\downarrow$ Methylation [35-38] \\
\hline FK506 binding protein 5 & FKBP5 & Various SNPs & $\begin{array}{l}\uparrow \text { risk with } r s 9470080 \\
\text { T allele; others mixed } \\
\text { findings }[39,40]\end{array}$ & & $\begin{array}{l}\downarrow \text { Methylation and } \\
\text { longitudinal } \\
\text { change }[41]\end{array}$ \\
\hline \multicolumn{6}{|l|}{ Other genes } \\
\hline $\begin{array}{l}\text { Pituitary adenylate } \\
\text { cyclase-activating } \\
\text { polypeptide type I } \\
\text { receptor }\end{array}$ & $A D C Y A P 1 R 1$ & rs2267735 & $\begin{array}{l}\uparrow \text { risk with } C \text { allele in } \\
\text { females }[42-44]\end{array}$ & $\begin{array}{l}\text { Blood, one loci in } \\
\text { promoter (using } \\
\text { HM27K array } \\
\text { data) }\end{array}$ & $\uparrow$ Methylation [42] \\
\hline Apolipoprotein E & $A P O E$ & rs7412, rs429358 & Mixed findings $^{\dagger}[45]$ & & $\mathrm{NI}$ \\
\hline $\begin{array}{l}\text { Brain-derived } \\
\text { neurotrophic factor }\end{array}$ & $B D N F$ & rs6265 & $\begin{array}{l}\uparrow \text { with A allele; others } \\
\text { no association }[46-48]\end{array}$ & $\begin{array}{l}\text { Saliva, exon IV } \\
\text { promoter }\end{array}$ & No association [49] \\
\hline Cannabinoid receptor & CNR1 & Various SNPs & No association ${ }^{\dagger}[50]$ & & $\mathrm{NI}$ \\
\hline $\begin{array}{l}\text { Catechol-O- } \\
\text { methyltransferase }\end{array}$ & COMT & $r s 4680$ & $\begin{array}{l}\uparrow \text { with } A \text { allele; others } \\
\text { no association }[51]\end{array}$ & $\begin{array}{l}\text { Blood, } 41 \text { loci } \\
\text { across gene } \\
\text { (using HM450K } \\
\text { array data) }\end{array}$ & $\begin{array}{l}\uparrow \text { Methylation with } \\
\text { fear inhibition in } \\
\text { PTSD [51] }\end{array}$ \\
\hline C-reactive protein & $C R P$ & rs1130864 & $\uparrow$ with T allele ${ }^{\dagger}[52]$ & & $\mathrm{NI}$ \\
\hline $\begin{array}{l}\text { Mannosidase alpha } \\
\text { class } 2 \mathrm{C} \text { member } 1\end{array}$ & MAN2 & $\mathrm{NI}$ & & & $\begin{array}{l}\text { No independent } \\
\text { association. Trauma } \\
\times \text { methylation } \\
\text { interaction [53] }\end{array}$ \\
\hline $\begin{array}{l}\uparrow: \text { Increased; } \downarrow \text { : Decreased. } \\
\text { 'Based on only a couple of stud } \\
\text { HM27K array: Methylation data } \\
\text { Infinium HumanMethylation } 450 \\
\text { UTR: Untranslated region; VNTR }\end{array}$ & 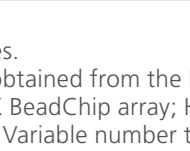 & $\begin{array}{l}\text { ium HumanMethyl } \\
\text { axis: Hypothalamic } \\
\text { em repeat. }\end{array}$ & 27 BeadChip array; HM45 & y: Methylation da & $\begin{array}{l}\text { tained from the } \\
\text { matic stress disorder; }\end{array}$ \\
\hline
\end{tabular}


Table 1. Candidate genes investigated in genetic or epigenetic studies of post-traumatic stress disorder (cont.).

\begin{tabular}{|c|c|c|c|c|c|}
\hline \multirow[t]{2}{*}{ Pathway and gene } & \multicolumn{3}{|c|}{ Gene-association studies } & \multicolumn{2}{|c|}{ DNA methylation studies } \\
\hline & Symbol & Region & Risk of PTSD & Tissue and sites & Risk of PTSD ${ }^{+}$ \\
\hline \multicolumn{6}{|l|}{ Other genes } \\
\hline Protein kinase $\mathrm{C}$ alpha & PRKCA & rs4790904 & Mixed findings [55,56] & & $\mathrm{NI}$ \\
\hline \multicolumn{6}{|c|}{$\begin{array}{l}\uparrow: \text { Increased; } \downarrow \text { : Decreased. } \\
\text { ¿Based on only a couple of studies. } \\
\text { HM27K array: Methylation data obtained from the Infinium HumanMethylation27 BeadChip array; HM450K array: Methylation data obtained from the } \\
\text { Infinium HumanMethylation450K BeadChip array; HPA-axis: Hypothalamic-pituitary-adrenal axis; NI: Not investigated; PTSD: Post-traumatic stress disorder; } \\
\text { UTR: Untranslated region; VNTR: Variable number tandem repeat. }\end{array}$} \\
\hline
\end{tabular}

In summary, despite some significant findings, very few of these have so far been successfully replicated [20]. This is likely caused in part by the differences in studies, with varying populations and exposures, as well as the likely small effect sizes which are easily drowned out by heterogeneous study designs. Publication bias would also suggest that there may be many more negative findings than those discussed here.

\section{Genome-wide association studies of PTSD}

Hypothesis-free genome-wide association studies (GWAS) aim to identify novel genes or gene pathways implicated in disease and hold particular promise for PTSD where the exact disease etiology remains unclear. However, only a handful of PTSD GWAS have so far been undertaken, the majority in US veterans or military personnel and their partners [74-79]. A number of novel loci and genes have been identified, although not always at genome-wide significant levels. This includes SNPs in PRTFDC1 [78], DSCAM [74], UNC13C [74], TLL1 [79], NLGN1 [76] and $R O R A$, as well as a long intergenic noncoding RNA [75,77]. None of these genes, however, have been identified across more than one GWAS study, and generally, the role of these genes in PTSD has not been clearly elucidated. NLGN1 encodes a protein involved in synaptogenesis and has previously been associated with autism. RORA encodes a protein that can protect neurons and glial cells for the neurotoxic effects of traumatic stress and it is expressed in brain regions such as the hypothalamus and cerebral cortex [77]. A more recent study of two independent cohorts with lifetime PTSD diagnosis failed to replicate the overall findings of $R O R A$, although a number of nominally significant associations were identified, including between rs11071587 and lifetime PTSD risk in Caucasian females [80]. This gene may therefore be a risk factor for the severity of PTSD symp- toms, rather than the disorder itself [81] or with other closely linked forms of psychopathology, such as the fear component of internalizing [82]. A recent study also found evidence that this gene is more closely associated with post-traumatic stress trajectories in individuals exposed to childhood physical abuse [83]. In a discovery sample of 147 military personal with and without PTSD following combat exposure, an intergenic SNP on chromosome 4, rs717947, was found to be associated with PTSD at genome-wide significant levels [84]. Interestingly this association was replicated in community women from the Grady Trauma Project, but not men. The risk variant was also associated with decreased medial and dorsolateral cortical activation to fearful faces, which may be considered as an endophenotype of PTSD.

\section{Gene-environment (trauma) interactions}

Genetic-association studies of PTSD are a special case of a gene-environment interaction, whereby genetic predisposition is considered together with a given environmental condition (trauma) and the risk of disease is determined. Genetic risk factors may interact with trauma to influence other health outcomes as well. One of the most widely cited studies in this area investigated the association between a high number of stressful events and clinical depression in young adults [85]. They reported a significant positive correlation, but only for individuals with the $S$ allele of 5-HTTLPR. Individuals with the $\mathrm{L}$ allele who experienced a high number of stressful events, had no increased depression risk. This research triggered a wave of subsequent studies but the results have not always been in concordance $[86,87]$ and debate about these findings is ongoing. Numerous other gene-environment interactions have also been reported for early-life trauma and genes previously implicated in behavior and psychiatric disorders. For example, boys who were maltreated 


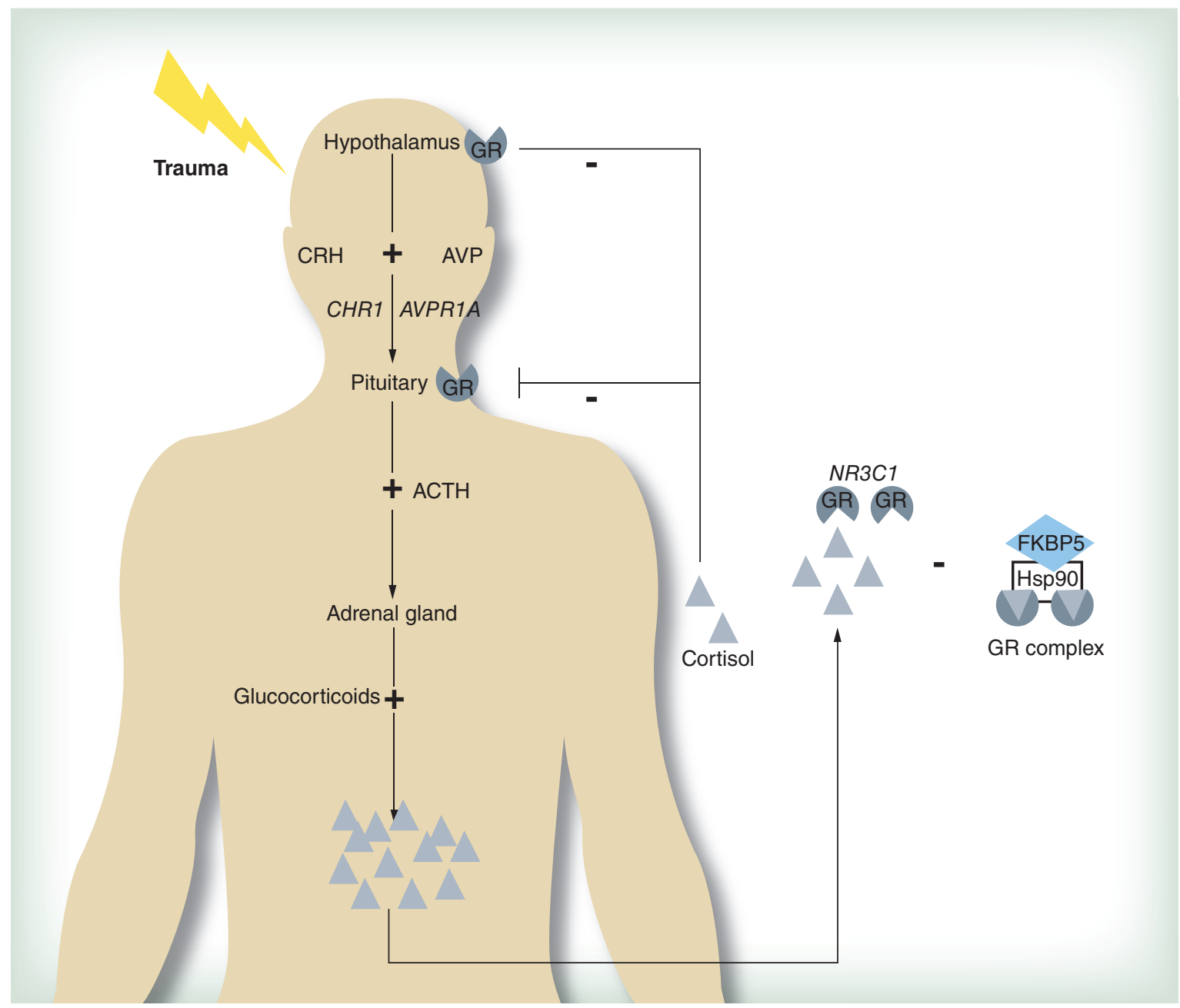

Figure 1. A simplified diagram showing some of the genes involved in hypothalamic-pituitary-adrenal axis signaling. The hypothalamic-pituitary-adrenal (HPA)-axis is one of the main signaling pathways activated in response to stress and trauma. These external cues are interpreted by the amygdala where it is processed and a distress signaling sent to the hypothalamus. CRH (or CRF) and AVP are released from the hypothalamic paraventricular nucleus and bind to their principal receptors, CRHR1 and AVPR1A. This in turn activates transcription of POMC, which is cleaved into ACTH and secreted from the anterior pituitary gland. In turn, this acts on the adrenal cortex to trigger release of glucocorticoids (e.g. cortisol) into the bloodstream. Upon binding of cortisol to the corticosteroid receptor, including the GR (encoded by NR3C1), this complex translocates into the nucleus and can bind to glucocorticoid responsive elements in the promoter regions of various target genes. This triggers the downstream signaling pathways which are necessary for the body's physiological response to stress. The functions of the GRs are partly moderated by chaperone-binding proteins. FKBP5 is a co-chaperone of Hsp90 and binds to the GR complex. When bound, the receptor has decreased affinity for cortisol and nuclear translocation is less efficient. FKBP5 thus plays an important role in the HPA-axis negative feedback loop and the levels of this protein increase in response to GR activation. The GR also plays a critical role in regulating the HPA-axis through a negative feedback loop, blocking further cortisol secretion.

ACTH: Adrenocorticotropic hormone; AVP: Arginine vasopressin; $\mathrm{CRH}$ : Corticotrophin-releasing hormone; GR: Glucocorticoid receptor.

and also carried a gene variant which results in lower $M A O A$ expression, had an increased risk of antisocial type behaviors in adulthood, but no such risk was observed for untreated boys with the same variant, or maltreated boys without this variant [88]. Once again this finding has not been clearly replicated [89], with most studies inadequately powered to detect such interactions. Despite this controversy, it remains clear that vulnerability to the effects of trauma and the risk of PTSD results from multiple independent, competing and interacting environmental and genetic factors. The question therefore remains of how trauma can have an enduring influence on disease risk, often lasting years, decades and even a lifetime after the actual events have occurred. More recent research has focused on the role of epigenetics in this regard. 


\section{The epigenome is responsive to trauma}

The epigenome is the collection of potentially reversible modifications that regulate the activity of genes without influencing the DNA sequence. In addition to being regulated by genetic factors, much of the epigenome is responsive to external influences throughout the lifecourse. This plasticity potentially enables optimal adaptation to changing environmental conditions. Exposure to trauma has considerable potential to impact the epigenome in a stable manner that may help explain the long-term effects of trauma on later health, including risk for psychiatric disorders $[90,91]$ and more specifically, PTSD.

The epigenome varies across cells and tissues, and rodent models have therefore been invaluable for investigating how trauma influences epigenetic patterns in the brain, given its central role in PTSD etiology. Such studies have examined the effects of exposure to early-life stress (e.g., prenatal stress, maternal behavior/care, separation) and stress in adulthood (e.g., fear conditioning, social defeat stress, chronic stress, and immobilization) on DNA methylation and/or histone modifications. Genes involved in neurogenesis and neuronal plasticity ( $B d n f$ and $G d n f)$ [92,93], as well as HPA-axis signaling (Crh; Crhrl; Nr3cl; Avp) [92,94-97], have been implicated. Effects are, however, brain region dependent [96].

The findings from experimental trauma studies in animals cannot readily be extrapolated to the human context, and access to human brain tissue is of course limited. Despite this, there has been an exponential increase over the last decade of human PTSD studies, thus far investigating DNA methylation patterns in peripheral tissue.

\section{DNA methylation patterns in PTSD}

Epigenome-wide association studies (EWAS) are similar to GWAS, in that they simultaneously investigate many thousands of loci across the genome. The primary aim of EWAS has been to identify DNA methylation differences at individual $\mathrm{CpG}$ sites or gene regions in individuals, in association with a specific phenotype or exposure. The first EWAS of PTSD used the Infinium HumanMethylation27 BeadChip (HM27K) Array (Illumina) to measure blood DNA methylation of more than 14,000 genes from 100 individuals in the Detroit Neighborhood Health Study [98]. All individuals had been exposed to at least one past traumatic event and 23 were diagnosed with lifetime PTSD. An overrepresentation of loci found to be differentially methylated between cases and controls was annotated to genes involved in immune system functions. Differential methylation at two genes encoding DNA methyltransferases, DNMT3B and DNMT3L, was also identified [98]. Only two subsequent EWAS studies have been undertaken, both from the Grady Trauma Project, although the analyzed sub-samples varied. One study measured blood methylation with the HM27K array in 50 individuals with PTSD and 50 controls matched for childhood trauma [99]. PTSD was associated with increased average methylation across all probes, and specific sites in five genes (TPR; CLEC9A; ACP5; ANXA2; TLR8) were found to be differentially methylated [99]. A number of identified genes have been linked with inflammation, supporting the initial EWAS findings, as well as prior observations that disrupted immune function is a feature of PTSD [100]. The second EWAS used the more recent Infinium HumanMethylation450K BeadChip (HM450K) array (Illumina) measuring DNA methylation at over 485,000 loci throughout the genome. Blood methylation profiles were compared between 32 current PTSD cases with a history of moderate to severe childhood abuse, 29 current PTSD cases with other lifetime traumas, and controls free of lifetime PTSD but matched for trauma exposure [101]. A number of differentially methylated loci were identified, particularly in SPON1 and TSPAN32 that almost completely distinguished the three groups. PTSD cases with a history of childhood abuse, in particular, showed the most distinct methylation patterns. Of note, these EWAS studies have all involved predominantly high-risk African-American populations, with low socioeconomic status and high rates of exposure to assaultive trauma. Sample sizes have almost universally been inadequate to reliably detect small effect sizes.

The most frequently investigated candidate gene is $N R 3 C 1$, primarily as differential $N R 3 C 1$ methylation has been reported following early-life stress and linked to stress sensitivity (Table 1) [102]. Among 122 combat veterans, NR3C1 blood methylation was negatively correlated with PTSD symptoms [35] and decreased NR3C1 methylation in blood has also been found in 30 individuals with current or past PTSD [36]. Similarly, increased NR3C1 methylation in saliva was associated with less intrusive traumatic memory and a decreased risk of PTSD in 83 male survivors of the Rwandan genocide [37]. It is hypothesized that decreased $\mathrm{NR} 3 \mathrm{Cl}$ methylation is linked with lower circulating cortisol levels, the end product of HPAaxis signaling (Figure 1), but this has not yet been adequately investigated. Another study of maternal PTSD severity $(\mathrm{n}=45)$ also found a negative correlation with NR3C1 methylation [38]. Likewise, maternal prefrontal cortical activation in response to video-stimuli which was negatively correlated with PTSD severity, was positively correlated with DNA methylation [38]. 
A number of other significant associations have also been reported, but none yet replicated. Complementing their findings of an association between $A D C Y$ APIR1 genetic variation and PTSD in women, Ressler et al. found a positive correlation between $A D C Y$ APIR1 blood methylation and total PTSD symptoms, although this finding was not sex specific [42]. In the same cohort, increased COMT methylation was observed in individuals with fear inhibition, an intermediate phenotype in PTSD [51]. Among 200 trauma exposed war veterans, PTSD symptom severity has been positively associated with blood methylation levels of $S K A 2$, which was identified as a promising biomarker of suicide risk [103]. Furthermore, methylation was shown to mediate in part the association between PTSD and reduced cortical thickness. Although not yet specifically replicated, another study found that an increase in SKA2 methylation corresponded with the emergence in PTSD symptoms in a Dutch military sample [57]. Interestingly, increased methylation of this gene has also been associated with lower cortisol stress reactivity [57], which is a common feature of PTSD [104] .

Other studies have reported a lack of independent associations between candidate gene methylation and PTSD, but have found that methylation levels modified the association between traumatic events and PTSD risk. For example, a positive association was found between the number of traumatic events and PTSD risk (diagnosis, severity and symptoms) in 100 individuals from the Detroit Neighborhood Health Study, but only for those with lower 5HTT promoter methylation levels [23]. Likewise in the same study, higher MAN2C1 methylation levels augmented the association between cumulative traumatic burden and lifetime PTSD [53]. Interestingly, while animal models of PTSD have implicated differential $B d n f$ methylation in the hippocampus [105], and hypermethylation of BDNF has been found in the brain of suicide victims compared with nonsuicide controls [106], only one human study has yet investigated epigenetic regulation of this gene in PTSD. This small study $(\mathrm{n}=48)$ which focused on interpersonal violence-related PTSD, found that $B D N F$ exon IV methylation was positively associated with maternal anxiety and brain activation, but not with PTSD [49].

Evidence is beginning to emerge of genetic and epigenetic interactions influencing PTSD risk. A study of 16 PTSD cases and 67 controls that investigated both genetic variation and DNA methylation of the DAT1 dopamine transporter gene found that the 9-repeat allele previously reported as a risk factor for PTSD, only increased risk when $D A T 1$ promoter methylation levels were high [21]. Individuals with the 9-repeat allele and low methylation levels had no increased risk. DNA methylation patterns of 5-HTTLPR have also been associated with an increased risk of unresolved loss or trauma, but only for individuals with the $\mathrm{L}$ allele [30] and 5-HTTLPR genetic-epigenetic interactions influence circulating cortisol levels in response to stress [31]. Recent evidence suggests that DNA methylation may be a mechanism by which specific genetic variants can influence the risk of PTSD. A functional polymorphism in the FKBP5 gene, for example, resulted in DNA demethylation of specific glucocorticoid response elements in this gene, and this led to an increased risk of developing PTSD following childhood trauma [41].

\section{Longitudinal studies}

While these studies have provided important information on the epigenetic profile of PTSD, the vast majority has been cross-sectional studies, making it impossible to determine whether the methylation marks proceed the development of PTSD or are a result of the disorder. Studies with longitudinally collect biospecimens are crucial, enabling the investigation of temporal changes in DNA methylation. In a cohort of US military personal deployed to the Middle East, blood DNA methylation of immune system-related genes was measured in 75 individuals pre- and postPTSD diagnosis, and in 75 military controls [107]. The degree of DNA methylation change was different between cases and controls for the long noncoding RNA transcript (H19) and IL-8. A similar study of 96 Dutch military measured DNA methylation pre- and post-deployment in Afghanistan using the HM450K array, and compared groups according to their level of trauma exposure, as well as the severity of PTSD symptoms [108]. Trauma was associated with increased DNA methylation age (a marker of accelerated epigenetic aging [109]), but interestingly, development of PTSD symptoms appeared to reverse this. Methylation data for individual loci were not reported. A small longitudinal study of psychotherapy in combat veterans with PTSD showed that NR3C1 blood methylation pretreatment, predicted treatment outcome but itself was not significantly altered post-treatment, in either responders $(n=8)$ or nonresponders $(n=8)$ [110]. Conversely, FKBP5 promoter methylation decreased with recovery, but pretreatment levels did not predict response [110], but clearly this sample size is too small to be conclusive. One of the only civilian samples to investigate longitudinal changes in DNA methylation, examined genes coding for DNA methyltransferease genes $(D N M T)$ pre- and post-trauma in 30 PTSD cases and 30 matched controls [111]. The investigators identified distinct DNA methylation marks following trauma in PTSD cases (DNMT1), but also potentially resilient marks present prior to trauma $(D N M T 3 B)$ and 
differentiated cases from controls [111]. Further work is clearly needed in larger sample sizes to determine the possibility of identifying a unique epigenetic signature which could help predict individuals at greatest risk of PTSD.

\section{Trauma exposure is associated with epigenetic modifications}

In addition to PTSD, trauma itself has been shown to alter DNA methylation patterns and early life has been highlighted as a particularly sensitive period of biological vulnerability. Indeed, trauma during critical periods of development in utero and early childhood is thought to be particularly important as epigenetic patterns are established, and the effects of trauma are more likely to become embedded, with long-term consequences [112]. Early-life trauma is also a major risk factor for later psychiatric disorders [113], including PTSD.

A couple of studies have investigated the effect of early-life trauma on DNA methylation in central tissue, focusing on the hippocampus given its direct involvement in stress signaling. In their study of postmortem brain tissue from 36 adult suicide victims, McGowan et al. found that a history of severe childhood abuse (ascertained with proxy-based interviews) was associated with increased hippocampal NR3C1 methylation [114]. An EWAS (HM450K array) also identified numerous genes that were differently methylated in the hippocampus of 25 men with a history of severe childhood abuse, compared with 16 nonabused controls [115]. The most significant genes mapped to pathways involved in neuronal plasticity, rather than HPA-axis signaling, with the top hit being ALS2 that regulates small GTPase activity [115]. This finding complements the results of neurobiology studies which have shown that epigenetic mechanisms play an important role in synaptic plasticity and the formation of memories [116], and intrusive memories are one of the hallmark features of PTSD.

The finding from McGowan, combined with the observation that prenatal stress was also associated with increased $N R 3 C 1$ methylation in peripheral tissue [117], led to a wave of subsequent candidate gene studies investigating epigenetic regulation of this gene in early-life trauma. Although the studies have been quite heterogeneous in terms of the type and timing of exposure (e.g., prenatal in utero stress exposure, trauma or adversity in childhood), the delay between exposure and the methylation measure, as well as the tissue investigated (i.e., cord blood, peripheral blood, placenta, buccal cells) there is now evidence for a relatively weak but consistent association between early-life trauma and increased NR3C1 methylation [102,118-119].
These findings are of particular relevance given that they align with the earlier observations in brain tissue, and suggest that, at least for some genes, peripheral epigenetic patterns may be a good reflection of changes occurring in relevant brain regions. Interestingly, however, the increased $\mathrm{NR} 3 \mathrm{Cl}$ methylation following early-life trauma, contrasts with decreased levels observed in PTSD [35,36]. This could fit with observations that trauma results in HPA-axis hyperactivation, but low circulating levels have been observed in PTSD.

A number of other studies provide preliminary evidence of an association between early-life trauma and candidate genes in peripheral tissue, such as 5-HTT [120], BDNF [121] and IGF2 [122], as well as genes involved in immune response [123]. EWAS, however, have provided the opportunity to identify novel genes. Parental stress predicted differences in buccal DNA methylation patterns (HM27K array) of genes involved in biosynthetic and metabolic processes in offspring adolescences [124]. These methylation differences varied depending on the sex of the child, and timing of stress exposure, with maternal stress having a greater effect in early infancy, while paternal stress was more predictive in the preschool years. A study of 96 maltreated children removed from their parents care, and 96 matched controls, identified 2868 loci which were differentially methylated across the genome (using the HM450K array) [125]. Many of the loci were intragenic and localized to genes previously associated with childhood diseases, for example asthma (FANK1), cancer (WNT3A), diabetes (PTPRN2) and cortical development $(C C D C 85 C)$.

DNA methylation has also been shown to play a role in stress regulation following exposure to traumatic events. A very recent EWAS identified a locus in KITLG as being differentially methylated following childhood trauma, and methylation of this gene mediated $32 \%$ of the association between early-life trauma and later stress reactivity [126]. This study initially involved 85 healthy adults and measured methylation in whole blood, followed by a replication sample of 45 individuals from an independent cohort and then a cross-tissue validation using buccal swabs from adolescents. Interestingly, this gene which is involved in cellular developmental processes has previously been linked with HPA-axis activity and has been shown to regulate the expression of $N R 3 C 1$ in erythroblasts [127].

Outside of the 'critical' early-life period, a number of studies have also reported associations between trauma and epigenetic marks. An EWAS of civilian atrisk African-Americans, failed to identify any genes which were differentially methylated between individuals exposed to childhood trauma and controls, but 
identified one loci, near NPFFR2 that distinguished individuals based on the total number of stressful events experienced over a lifetime [99]. This neurotransmitter has previously been implicated in PTSD [73]. In the same population, cumulative life stress was a stronger predictor of accelerated epigenetic aging compared with childhood trauma or current stress [128].

Again genes involved in HPA-axis signaling (Figure 1) have been strong candidates for studies in this area. In keeping with the earlier findings concerning $N R 3 C 1$, stressful life events in adolescence have also been associated with increased NR3C1 blood methylation, independently of childhood trauma [129]. Furthermore, a study of 32 Holocaust survivors and their adult offspring, as well as eight control parent-child dyads, found that Holocaust exposure was associated with differentially $F K B P 5$ methylation. Interestingly, while lower FKBP5 methylation was observed in those exposed individuals, compared with the controls, the offspring of Holocaust survivors actually had higher methylation levels than the offspring of nonexposed individuals [130]. These findings may represent an adaptation of the next, but further work is needed to investigate the underlying mechanisms for this intergenerational transmission.

\section{Limitations of genetic \& epigenetic association studies of PTSD}

Over the last decade there has been considerable increase in research aimed at advancing our knowledge of the genetic and epigenetic underpinnings of trauma and PTSD. While the findings presented here provide evidence for the involvement of specific gene and gene pathways, many of which are supported by their known involvement in key biological systems disrupted in PTSD, there are also a number of limitations to this research and caution must also be taken in the interpretation of findings to date. Overall, there has been a general lack of clearly replicable findings, which may be partly accounted for by the inherent statistical limitations of the generally small studies. Differences are also likely to relate to the heterogeneity of the populations (ethnicity, gender, age, clinical vs community samples), and the trauma experienced (type, number, severity and timing). These cumulative differences across studies are especially problematic for the consistent detection of small effect sizes often reported as initial findings. Of note, the vast majority of studies presented here involved either Caucasian males in the military with combat exposure, or African-American heavily traumatized populations in the USA. While these studies have contributed crucial insights in this area, whether or not these findings can be extrapolated to other populations and contexts remains to be determined. Of further note, although women are less likely to experience most types of traumatic events than men (with some notable exceptions), they have higher rates of PTSD. Sex-specific epigenetic changes in the brain, largely driven by steroid hormones, may help account for this differing vulnerability. Mounting evidence, largely from animal studies suggests that differing environmental exposures often show sexually dimorphic effects on the epigenome, but this requires considerable more investigation in humans.

Genetic- and epigenetic-association studies of PTSD also have unique complexities which must be considered in the study design and interpretation of findings. PTSD is a highly heterogeneous condition which can present itself differently across individuals. Cases can be defined based on PTSD diagnosis or the presence of specific PTSD symptoms, current or lifetime diagnosis and first episodes or recurrent PTSD, thus contributing to large heterogeneity across studies. The selection of the most appropriate controls for these studies also remains a difficult yet important consideration, as they cannot be easily sampled from the wider population. By definition a PTSD diagnosis requires a previous trauma to have occurred, and controls must therefore be sampled from those having experienced a similar trauma but without developing PTSD, normally within a given timeframe since the event. This selection strategy also helps minimize risk factors (including genetic) which are associated with the likelihood of exposure, rather than or as well as the risk of PTSD. Natural disasters provide a perfect platform for this type of study, but are not without their own challenges. In addition to the obvious difficulties arising in these environments, ensuring adequate matching on the severity and duration of trauma can be problematic, as well as other environmental factors such as socio-support and economic status, which may themselves influence PTSD risk. Prospective exposed cohort designs can be very useful, where, for example, participants are recruited from hospital emergency wards after a trauma exposure. However, recruiting samples large enough for genetic analysis remains an issue. Another difficulty concerns the considerable overlap in the heritability of PTSD with other psychiatric disorders [9] that could share genetic risk factors.

Finally, when investigating the possible involvement of epigenetic processes involved in trauma and PTSD, human post-mortem studies of brain tissue are particular relevant. Unlike genetic marks, epigenetic patterns are tissue and cell specific, and the brain would thus be the most appropriate tissue for disorders involving central processes. However, post-mortem studies are not without their own limitations, which includes confounding related to the cause of death (including 
possible comorbid psychiatric disorders like depression), the timing and condition under which the sample is obtained, the lack of detailed patient history including information on the trauma itself and diagnosis of other psychiatric conditions and the fact that findings from such studies will only ever be correlational (i.e., lacking a prospective design to help ascertain causality). Conversely, the usefulness of peripheral epigenetic markers in complex neurobiological phenotypes and brain disorders is now well recognized [90]. This may be particularly relevant for trauma which is known to impact on a range of biological systems involving humoral mechanisms, including stress reactivity and HPA axis, or associated inflammatory response.

\section{Conclusion}

Individuals differ in their vulnerability for PTSD and through a growing number of GWAS, several novel genetic risk factors have now been identified. There is now consistent evidence that early-life trauma can result in changes in DNA methylation patterns in both central and peripheral tissue. Individuals with PTSD have also been found to carry a unique DNA methylation signature, however, whether this can be used to predict risk of PTSD or is a consequence of the disease process, remains to be determined. Furthering our knowledge of the genetic and epigenetic architecture underlying response to trauma and risk for PTSD will enhance our understanding of disease etiology and could enable the early identification of vulnerable individuals, with the future possibility of targeted preventative interventions. Given that epigenetic processes are dynamic in nature and highly sensitive to environmental cues, there is great promise that appropriate interventions could help counteract or reverse the negative effects of trauma, building resilience through changes in gene activity.

\section{Future perspective}

Over the next $5-10$ years there will be a greater shift away from individual candidate gene analysis to studies focused on groups of genes in common biological pathways, and larger genome-wide analysis. GWAS and EWAS investigate hundreds of thousands of genetic loci which are analyzed individually and stringent criteria must therefore be used to account for the multiple testing. The predominantly small studies to date have been underpowered to detect the likely small risk ratios and effect sizes, and much larger samples are therefore essential. Current estimates based on other psychiatric disorders suggest that future GWAS studies will need to involve 10,000 or more participants if variants are to be identified at the necessary corrected levels of significance [131]. EWAS are more favorably powered owing to the continuous nature of methylation data (compared with gene frequencies), but other data complexities (e.g., large variances, uneven distributions) ensure that large samples are also needed to generate robust findings. This is where consortium, such as the Psychiatric Genetics Consortium PTSD group [132], will become essential to advance research in this area. Such consortium will also provide a platform to integrate GWAS and EWAS data, which is a crucial next step for research in this field.

Large prospective studies which can adequately control for the various bias inherent in these types of studies (as discussed previously), are now needed. There have been some promising findings from the few longitudinal epigenetic studies so far undertaken, and it is likely that an increasing number of prospective cohorts will collect biological samples at multiple time-points, enabling temporal epigenetic changes to be examined. This is particularly important to differentiate between DNA methylation marks which proceed PTSD, rather than those which are a consequence. Early biomarkers of at-risk individuals are particularly interesting, given their potential clinical utility. This could include administering early pharmacological treatments or cognitive-behavioral interventions to the most vulnerable individuals following exposure to major trauma, which could reduce the risk of subsequent PTSD. For example, medication records showed that US military personnel who received morphine in post-trauma care had lower rates of PTSD than personnel that did not receive treatment [73]. Such treatment may therefore be particularly beneficial in individuals with biomarkers indicating that they are already at an increased risk of PTSD. Molecular biomarkers could also be used to monitor the effectiveness of treatment interventions. In the broader field of epigenetics, a lot of attention is also being paid to new epigenetic therapies. Histone deacetylase inhibitors, for example, have been shown to reverse deficits in stress-related behaviors, as well as synaptic plasticity, learning and memory. Again, these treatments may prove to be most beneficial in certain individuals, such as those at-risk of PTSD [133]. However, more work is first required to establish the biological relevance of differences in peripheral methylation patterns observed in PTSD or trauma, by investigating whether they are associated with functional changes in gene expression and protein levels. For example, although some recent findings are starting to emerge [57,126], there are a lack of studies investigating how epigenetic factors can be linked directly with cortisol levels or stress reactivity in PTSD. Furthermore, determining how peripheral epigenetic marks correlate with methylation and 
expression patterns in brain tissue will be essential to understand their possible involvement in disease etiology.

Financial \& competing interests disclosure

The authors have no relevant affiliations or financial involvement with any organization or entity with a financial interest in or financial conflict with the subject matter or materials discussed in the manuscript. This includes employment, consultancies, honoraria, stock ownership or options, expert testimony, grants or patents received or pending, or royalties. No writing assistance was utilized in the production of this manuscript.

\section{Open access}

This work is licensed under the Attribution-NonCommercialNoDerivatives 4.0 Unported License. To view a copy of this license, visit http://creativecommons.org/licenses/by-nc-nd/4.0/

\section{Executive summary}

Heritability of trauma \& post-traumatic stress disorder

- The heritability of post-traumatic stress disorder (PTSD) is estimated at up to $35 \%$, but varies widely when individual PTSD symptoms are examined.

- The risk of experiencing certain types of traumas may also have a substantial genetic component.

Genetic risk variants for PTSD

- More than 25 genes have been identified for their involvement in PTSD.

- The majority of genetic studies have been candidate gene, focusing on genes involved in neurotransmitter systems and stress signaling.

Genome-wide association studies of PTSD

- Six genome-wide association studies of PTSD have so far been undertaken and a number of novel loci have been identified.

- None of the top hits have been found in more than one genome-wide association studies, although the RORA is a biologically plausible gene, which has also been associated with closely related phenotypes in other candidate studies.

Gene-environment (trauma) interactions

- PTSD is unique in that its etiology is directly linked to having experienced a trauma.

- The effects of trauma on other health outcomes can also be influenced by genetic susceptibility.

The epigenome is responsive to trauma

- Trauma is likely to have an impact on the epigenome and could help explain the long-lasting effects on later health.

- Animal studies provide good experimental support for a direct link between epigenetic modifications and PTSD. DNA methylation patterns in PTSD

- A number of predominantly small studies have compared epigenome-wide methylation patterns between PTSD cases and controls, and genes involved with immune system function have been implicated.

- Numerous candidate genes have been found to be differentially methylated in PTSD, but to date, have only been investigated in a few studies.

- Genetic variation in combination with specific DNA methylation patterns, can influence the risk of PTSD.

Longitudinal studies

- Recent longitudinal studies have begun to investigate how DNA methylation changes with the development of PTSD.

Trauma exposure is associated with epigenetic modifications

- Early-life trauma influences both central and peripheral DNA methylation, with the most consistent evidence implicating the glucocorticoid receptor NR3C1.

- Trauma occurring outside of the early-life period, has also been associated with differential methylation.

Limitations of genetic \& epigenetic association studies of PTSD

- The vast majority of findings have come from studies of at-risk African-American populations, with high PTSD rates, or white Caucasian males exposed to war trauma.

- The unique complexities of PTSD must be considered in the design of future studies and when interpreting the results to date.

- DNA methylation patterns in peripheral tissue have potential utility as biomarkers of PTSD risk, however, they are unlikely to inform knowledge of disease etiology.

\section{References}

Papers of special note have been highlighted as:

- of interest; $\bullet \bullet$ of considerable interest
1 Bonanno GA. Loss, trauma, and human resilience: have we underestimated the human capacity to thrive after extremely aversive events? Am. Psychol. 59(1), 20-28 (2004). 
2 Bisson JI, Cosgrove S, Lewis C, Robert NP. Post-traumatic stress disorder. BMJ 351, h6161 (2015).

3 American Psychiatric Association. Diagnostic And Statistical Manual Of Mental Disorders (5th Edition). American Psychiatric Publishing, VA, USA (2013).

4 Hauffa R, Rief W, Brahler E, Martin A, Mewes R, Glaesmer H. Lifetime traumatic experiences and posttraumatic stress disorder in the German population: results of a representative population survey. J. Nerv. Ment. Dis. 199(12), 934-939 (2011).

5 Reynolds K, Pietrzak RH, Mackenzie CS, Chou KL, Sareen J. Post-traumatic stress disorder across the adult lifespan: findings from a nationally representative survey. Am. J. Geriatr. Psychiatry 24(1), 81-93 (2016).

6 Darves-Bornoz JM, Alonso J, De Girolamo G et al. Main traumatic events in Europe: PTSD in the European study of the epidemiology of mental disorders survey. J. Trauma Stress 21(5), 455-462 (2008).

7 Creamer M, Burgess P, McFarlane AC. Post-traumatic stress disorder: findings from the Australian National Survey of Mental Health and Well-being. Psychol. Med. 31(7), 1237-1247 (2001).

8 Yehuda R, Halligan SL, Bierer LM. Relationship of parental trauma exposure and PTSD to PTSD, depressive and anxiety disorders in offspring. J. Psychiatr. Res. 35(5), 261-270 (2001).

9 Sartor CE, Grant JD, Lynskey MT et al. Common heritable contributions to low-risk trauma, high-risk trauma, posttraumatic stress disorder, and major depression. Arch. Gen. Psychiatry 69(3), 293-299 (2012).

- An important study which calculates the proportion of variance in risk explained by genetic and environmental factors, for different types of trauma and post-traumatic stress disorder (PTSD), as well as the degree of overlap between these factors.

10 Lyons MJ, Goldberg J, Eisen SA et al. Do genes influence exposure to trauma? A twin study of combat. Am. J. Med. Genet. 48(1), 22-27 (1993).

11 True WR, Rice J, Eisen SA et al. A twin study of genetic and environmental contributions to liability for post-traumatic stress symptoms. Arch. Gen. Psychiatry 50(4), 257-264 (1993).

12 Stein MB, Jang KL, Taylor S, Vernon PA, Livesley WJ. Genetic and environmental influences on trauma exposure and post-traumatic stress disorder symptoms: a twin study. Am. J. Psychiatry 159(10), 1675-1681 (2002).

13 Jang KL, Stein MB, Taylor S, Asmundson GJ, Livesley WJ Exposure to traumatic events and experiences: aetiological relationships with personality function. Psychiatry Res. 120(1), 61-69 (2003).

14 Amstadter AB, Aggen SH, Knudsen GP, ReichbornKjennerud T, Kendler KS. A population-based study of familial and individual-specific environmental contributions to traumatic event exposure and post-traumatic stress disorder symptoms in a Norwegian twin sample. Twin Res. Hum. Genet. 15(5), 656-662 (2012).
15 Dragan WL, Oniszczenko W. The association between dopamine D4 receptor exon III polymorphism and intensity of PTSD symptoms among flood survivors. Anxiety Stress Coping 22(5), 483-495 (2009).

16 Nelson EC, Heath AC, Lynskey MT et al. PTSD risk associated with a functional $D R D 2$ polymorphism in heroindependent cases and controls is limited to amphetaminedependent individuals. Addict. Biol. 19(4), 700-707 (2014).

17 Comings DE, Muhleman D, Gysin R. Dopamine D2 receptor $(D R D 2)$ gene and susceptibility to post-traumatic stress disorder: a study and replication. Biol. Psychiatry 40(5), 368-372 (1996).

18 Young RM, Lawford BR, Noble EP et al. Harmful drinking in military veterans with post-traumatic stress disorder: association with the $\mathrm{D} 2$ dopamine receptor $\mathrm{A} 1$ allele. Alcohol Alcohol. 37(5), 451-456 (2002).

19 Voisey J, Swagell CD, Hughes IP et al. The DRD2 gene 957C $>\mathrm{T}$ polymorphism is associated with post-traumatic stress disorder in war veterans. Depress. Anxiety 26(1), 28-33 (2009)

20 Voisey J, Young RM, Lawford BR, Morris CP. Progress towards understanding the genetics of post-traumatic stress disorder. J. Anxiety Disord. 28(8), 873-883 (2014).

21 Chang SC, Koenen KC, Galea S et al. Molecular variation at the SLC6A3 locus predicts lifetime risk of PTSD in the Detroit Neighborhood Health Study. PLoS ONE 7(6), e39184 (2012).

22 Drury SS, Theall KP, Keats BJ, Scheeringa M. The role of the dopamine transporter (DAT) in the development of PTSD in preschool children. J. Trauma Stress 22(6), 534-539 (2009).

23 Koenen KC, Uddin M, Chang SC et al. SLC6A4 methylation modifies the effect of the number of traumatic events on risk for post-traumatic stress disorder. Depress. Anxiety 28(8), 639-647 (2011).

24 Mellman TA, Alim T, Brown DD et al. Serotonin polymorphisms and post-traumatic stress disorder in a trauma exposed African-American population. Depress. Anxiety 26(11), 993-997 (2009).

25 Cornelis MC, Nugent NR, Amstadter AB, Koenen KC. Genetics of post-traumatic stress disorder: review and recommendations for genome-wide association studies. Curr. Psychiatry Rep. 12(4), 313-326 (2010).

26 Koenen KC, Aiello AE, Bakshis E et al. Modification of the association between serotonin transporter genotype and risk of post-traumatic stress disorder in adults by county-level social environment. Am. J. Epidemiol. 169(6), 704-711 (2009).

27 Kilpatrick DG, Koenen KC, Ruggiero KJ et al. The serotonin transporter genotype and social support and moderation of post-traumatic stress disorder and depression in hurricaneexposed adults. Am. J. Psychiatry 164(11), 1693-1699 (2007).

28 Xie P, Kranzler HR, Poling J et al. Interactive effect of stressful life events and the serotonin transporter 5-HTTLPR genotype on post-traumatic stress disorder diagnosis in 2 independent populations. Arch. Gen. Psychiatry 66(11), 1201-1209 (2009). 
29 Gressier F, Calati R, Balestri M et al. The 5-HTTLPR polymorphism and post-traumatic stress disorder: a metaanalysis. J. Trauma Stress 26(6), 645-653 (2013).

30 Van IMH, Caspers K, Bakermans-Kranenburg MJ, Beach SR, Philibert R. Methylation matters: interaction between methylation density and serotonin transporter genotype predicts unresolved loss or trauma. Biol. Psychiatry 68(5), 405-407 (2010).

31 Alexander N, Wankerl M, Hennig J et al. DNA methylation profiles within the serotonin transporter gene moderate the association of 5-HTTLPR and cortisol stress reactivity. Transl. Psychiatry. 4, e443 (2014).

32 White S, Acierno R, Ruggiero KJ et al. Association of CRHR1 variants and post-traumatic stress symptoms in hurricane exposed adults. J. Anxiety Disord. 27(7), 678-683 (2013).

33 Dunn EC, Solovieff N, Lowe SR et al. Interaction between genetic variants and exposure to Hurricane Katrina on posttraumatic stress and post-traumatic growth: a prospective analysis of low income adults. J. Affect. Disord. 152-154, 243-249 (2014).

34 Bachmann AW, Sedgley TL, Jackson RV, Gibson JN, Young RM, Torpy DJ. Glucocorticoid receptor polymorphisms and post-traumatic stress disorder. Psychoneuroendocrinology 30(3), 297-306 (2005).

35 Yehuda R, Flory JD, Bierer LM et al. Lower methylation of glucocorticoid receptor gene promoter $1 \mathrm{~F}$ in peripheral blood of veterans with post-traumatic stress disorder. Biol. Psychiatry 77(4), 356-364 (2015).

36 Labonte B, Azoulay N, Yerko V, Turecki G, Brunet A. Epigenetic modulation of glucocorticoid receptors in posttraumatic stress disorder. Transl. Psychiatry. 4, e368 (2014).

37 Vukojevic V, Kolassa IT, Fastenrath M et al. Epigenetic modification of the glucocorticoid receptor gene is linked to traumatic memory and post-traumatic stress disorder risk in genocide survivors. J. Neurosci. 34(31), 10274-10284 (2014).

38 Schechter DS, Moser DA, Paoloni-Giacobino A et al. Methylation of NR3C1 is related to maternal PTSD, parenting stress and maternal medial prefrontal cortical activity in response to child separation among mothers with histories of violence exposure. Front. Psychol. 6, 690 (2015).

39 Binder EB, Bradley RG, Liu W et al. Association of FKBP5 polymorphisms and childhood abuse with risk of post-traumatic stress disorder symptoms in adults. JAMA 299(11), 1291-1305 (2008).

40 Xie P, Kranzler HR, Poling J et al. Interaction of FKBP5 with childhood adversity on risk for post-traumatic stress disorder. Neuropsychopharmacology 35(8), 1684-1692 (2010).

41 Klengel T, Mehta D, Anacker C et al. Allele-specific FKBP5 DNA demethylation mediates gene-childhood trauma interactions. Nat. Neurosci. 16(1), 33-41 (2013).

- A landmark paper demonstrating that the increased risk of PTSD following childhood trauma is influenced by a functional polymorphism in $F K B P 5$ which results in DNA demethylation of specific glucocorticoid-responsive elements in the gene, influencing stress signaling.
42 Ressler KJ, Mercer KB, Bradley B et al. Post-traumatic stress disorder is associated with PACAP and the PAC1 receptor. Nature 470 (7335), 492-497 (2011).

43 Almli LM, Mercer KB, Kerley Ket al. ADCYAPIR1 genotype associates with post-traumatic stress symptoms in highly traumatized African-American females. Am. J. Med. Genet. B Neuropsychiatr. Genet. 162b(3), 262-272 (2013).

44 Wang L, Cao C, Wang R, Qing Y, Zhang J, Zhang XY. $\mathrm{PAC1}$ receptor (ADCYAP1R1) genotype is associated with PTSD's emotional numbing symptoms in Chinese earthquake survivors. J. Affect. Disord. 150 (1), 156-159 (2013).

45 Kim TY, Chung HG, Shin HS et al. Apolipoprotein E gene polymorphism, alcohol use, and their interactions in combatrelated post-traumatic stress disorder. Depress. Anxiety 30(12), 1194-1201 (2013).

46 Pivac N, Kozaric-Kovacic D, Grubisic-Ilic M et al. The association between brain-derived neurotrophic factor Val66Met variants and psychotic symptoms in post-traumatic stress disorder. World J. Biol Psychiatry 13(4), 306-311 (2012).

47 Felmingham KL, Dobson-Stone C, Schofield PR, Quirk GJ, Bryant RA. The brain-derived neurotrophic factor Val66Met polymorphism predicts response to exposure therapy in posttraumatic stress disorder. Biol. Psychiatry 73(11), 1059-1063 (2013).

48 Zhang H, Ozbay F, Lappalainen J et al. Brain derived neurotrophic factor $(B D N F)$ gene variants and Alzheimer's disease, affective disorders, post-traumatic stress disorder, schizophrenia, and substance dependence. Am. J. Med. Genet. B Neuropsychiatr. Genet. 141b(4), 387-393 (2006).

49 Moser DA, Paoloni-Giacobino A, Stenz L et al. BDNF methylation and maternal brain activity in a violence-related sample. PLoS ONE 10(12), e0143427 (2015).

50 Lu AT, Ogdie MN, Jarvelin MR et al. Association of the cannabinoid receptor gene (CNR1) with ADHD and post-traumatic stress disorder. Am. J. Med. Genet. B Neuropsychiatr. Genet. 147b(8), 1488-1494 (2008).

51 Norrholm SD, Jovanovic T, Smith AK et al. Differential genetic and epigenetic regulation of catechol-Omethyltransferase is associated with impaired fear inhibition in post-traumatic stress disorder. Front. Behav. Neurosci. 7 , 30 (2013).

52 Michopoulos V, Rothbaum AO, Jovanovic T et al. Association of CRP genetic variation and CRP level with elevated PTSD symptoms and physiological responses in a civilian population with high levels of trauma. Am. J. Psychiatry 172(4), 353-362 (2015).

53 Uddin M, Galea S, Chang SC et al. Gene expression and methylation signatures of $M A N 2 C 1$ are associated with PTSD. Dis. Markers. 30(2-3), 111-121 (2011).

54 Andero R, Brothers SP, Jovanovic T et al. Amygdaladependent fear is regulated by Oprl1 in mice and humans with PTSD. Sci. Transl. Med. 5(188), 188ra173 (2013).

55 De Quervain DJ, Kolassa IT, Ackermann S et al. PKCalpha is genetically linked to memory capacity in healthy subjects and to risk for post-traumatic stress disorder in genocide survivors. Proc. Natl Acad. Sci. USA 109(22), 8746-8751 (2012). 

Beckham JC. Association of variant rs4790904 in protein kinase $\mathrm{C}$ alpha with post-traumatic stress disorder in a U.S. Caucasian and African-American veteran sample. J Depress. Anxiety 2(1), S4001 (2013).

57 Boks MP, Rutten BP, Geuze E et al. SKA2 methylation is involved in cortisol stress reactivity and predicts the development of post-traumatic stress disorder (PTSD) after military deployment. Neuropsychopharmacology 41(5), 1350-1356 (2016).

58 Belujon P, Grace AA. Regulation of dopamine system responsivity and its adaptive and pathological response to stress. Proc. Biol. Sci. 282(1805), 20142516 (2015).

59 Nagano-Saito A, Dagher A, Booij L et al. Stress-induced dopamine release in human medial prefrontal cortex $-18 \mathrm{~F}$ fallypride/PET study in healthy volunteers. Synapse 67(12), 821-830 (2013).

60 Pruessner JC, Champagne F, Meaney MJ, Dagher A. Dopamine release in response to a psychological stress in humans and its relationship to early life maternal care: a positron emission tomography study using [11C] raclopride. J. Neurosci. 24(11), 2825-2831 (2004).

61 Lawford BR, Barnes M, Swagell CD et al. DRD2/ANKK1 Taq1A (rs 1800497 C>T) genotypes are associated with susceptibility to second generation antipsychotic-induced akathisia. J. Psychopharmacol. 27(4), 343-348 (2013).

62 Davis LL, Suris A, Lambert MT, Heimberg C, Petty F. Post-traumatic stress disorder and serotonin: new directions for research and treatment. J. Psychiatry Neurosci. 22(5), 318-326 (1997).

63 Schneier FR, Campeas R, Carcamo J et al. Combined mirtazapine and SSRI treatment of PTSD: a placebocontrolled trial. Depress. Anxiety 32(8), 570-579 (2015).

64 Wendland JR, Martin BJ, Kruse MR, Lesch KP, Murphy DL. Simultaneous genotyping of four functional loci of human SLC6A4, with a reappraisal of 5-HTTLPR and rs25531. Mol. Psychiatry 11(3), 224-226 (2006).

65 Grabe HJ, Spitzer C, Schwahn C et al. Serotonin transporter gene (SLC6A4) promoter polymorphisms and the susceptibility to post-traumatic stress disorder in the general population. Am. J. Psychiatry 166(8), 926-933 (2009).

66 Thakur GA, Joober R, Brunet A. Development and persistence of post-traumatic stress disorder and the 5-HTTLPR polymorphism. J. Trauma Stress 22(3), 240-243 (2009).

67 Kim-Cohen J, Turkewitz R. Resilience and measured gene-environment interactions. Dev. Psychopathol. 24(4), 1297-1306 (2012)

68 Wilker S, Pfeiffer A, Kolassa S et al. The role of FKBPS genotype in moderating long-term effectiveness of exposurebased psychotherapy for post-traumatic stress disorder. Transl. Psychiatry 4, e403 (2014).

69 Hammack SE, Cheung J, Rhodes KM et al. Chronic stress increases pituitary adenylate cyclase-activating peptide (PACAP) and brain-derived neurotrophic factor (BDNF) mRNA expression in the bed nucleus of the stria terminalis (BNST): roles for PACAP in anxiety-like behavior. Psychoneuroendocrinology 34(6), 833-843 (2009).
70 Stroth N, Holighaus Y, Ait-Ali D, Eiden LE. PACAP: a master regulator of neuroendocrine stress circuits and the cellular stress response. Ann. NY Acad. Sci. 1220, 49-59 (2011).

71 Niknazar S, Nahavandi A, Peyvandi AA, Peyvandi H, Akhtari AS, Karimi M. Comparison of the adulthood chronic stress effect on hippocampal BDNF signaling in male and female rats. Mol. Neurobiol. 53(6), 4026-4033 (2015).

72 Martinotti G, Sepede G, Brunetti M et al. BDNF concentration and impulsiveness level in post-traumatic stress disorder. Psychiatry Res. 229(3), 814-818 (2015).

73 Holbrook TL, Galarneau MR, Dye JL, Quinn K, Dougherty AL. Morphine use after combat injury in Iraq and post-traumatic stress disorder. N. Engl. J. Med. 362(2), 110-117 (2010).

74 Ashley-Koch AE, Garrett ME, Gibson J et al. Genome-wide association study of post-traumatic stress disorder in a cohort of Iraq-Afghanistan era veterans. J. Affect. Disord. 184, 225-234 (2015).

75 Guffanti G, Galea S, Yan L et al. Genome-wide association study implicates a novel RNA gene, the lincRNA AC068718.1, as a risk factor for post-traumatic stress disorder in women. Psychoneuroendocrinology 38(12), 3029-3038 (2013).

76 Kilaru V, Iyer SV, Almli LM et al. Genome-wide genebased analysis suggests an association between Neuroligin 1 (NLGN1) and post-traumatic stress disorder. Transl. Psychiatry 6, e820 (2016).

77 Logue MW, Baldwin C, Guffanti G et al. A genome-wide association study of post-traumatic stress disorder identifies the retinoid-related orphan receptor alpha $(R O R A)$ gene as a significant risk locus. Mol. Psychiatry 18(8), 937-942 (2013).

- This is the first genome-wide association study of PTSD involving 295 cases, which identify several SNPs in the retinoid-related orphan receptor alpha gene and replicated some of these in two independent cohorts.

78 Nievergelt CM, Maihofer AX, Mustapic M et al. Genomic predictors of combat stress vulnerability and resilience in U.S. marines: a genome-wide association study across multiple ancestries implicates PRTFDC1 as a potential PTSD gene. Psychoneuroendocrinology 51, 459-471 (2015)

79 Xie P, Kranzler HR, Yang C, Zhao H, Farrer LA, Gelernter J. Genome-wide association study identifies new susceptibility loci for post-traumatic stress disorder. Biol. Psychiatry 74(9), 656-663 (2013).

80 Guffanti G, Ashley-Koch AE, Roberts AL et al. No association between RORA polymorphisms and PTSD in two independent samples. Mol. Psychiatry 19(10), 1056-1057 (2014).

81 Amstadter AB, Sumner JA, Acierno R et al. Support for association of RORA variant and post traumatic stress symptoms in a population-based study of hurricane exposed adults. Mol. Psychiatry 18(11), 1148-1149 (2013).

82 Miller MW, Wolf EJ, Logue MW, Baldwin CT. The retinoidrelated orphan receptor alpha $(R O R A)$ gene and fear-related psychopathology. J. Affect. Disord. 151(2), 702-708 (2013). 
83 Lowe SR, Meyers JL, Galea S et al. RORA and post-traumatic stress trajectories: main effects and interactions with childhood physical abuse history. Brain Behav. 5(4), e00323 (2015).

84 Almli LM, Stevens JS, Smith AK et al. A genome-wide identified risk variant for PTSD is a methylation quantitative trait locus and confers decreased cortical activation to fearful faces. Am. J. Med. Genet. B Neuropsychiatr. Genet. 168b(5), 327-336 (2015).

85 Caspi A, Sugden K, Moffitt TE et al. Influence of life stress on depression: moderation by a polymorphism in the $5-H T T$ gene. Science 301(5631), 386-389 (2003).

86 Karg K, Burmeister M, Shedden K, Sen S. The serotonin transporter promoter variant $(5-H T T L P R)$, stress, and depression meta-analysis revisited: evidence of genetic moderation. Arch. Gen. Psychiatry 68(5), 444-454 (2011).

87 Risch N, Herrell R, Lehner T et al. Interaction between the serotonin transporter gene (5-HTTLPR), stressful life events, and risk of depression: a meta-analysis. JAMA 301(23), 2462-2471 (2009).

88 Caspi A, McClay J, Moffitt TE et al. Role of genotype in the cycle of violence in maltreated children. Science 297(5582), 851-854 (2002).

89 Nilsson KW, Comasco E, Hodgins S, Oreland L, Aslund C. Genotypes do not confer risk for delinquency but rather alter susceptibility to positive and negative environmental factors: gene-environment interactions of BDNF Val66Met, 5-HTTLPR, and MAOA-uVNTR [corrected]. Int. J. Neuropsychopharmacol. 18(5), pii: pyu107 (2015).

90 Januar V, Saffery R, Ryan J. Epigenetics and depressive disorders: a review of current progress and future directions. Int. J. Epidemiol. 44(4), 1364-1387 (2015).

91 Petronis A. Epigenetics as a unifying principle in the aetiology of complex traits and diseases. Nature 465(7299), 721-727 (2010).

92 Boersma GJ, Lee RS, Cordner ZA et al. Prenatal stress decreases $B d n f$ expression and increases methylation of Bdnf exon IV in rats. Epigenetics 9(3), 437-447 (2014).

93 Uchida S, Hara K, Kobayashi A et al. Epigenetic status of $G d n f$ in the ventral striatum determines susceptibility and adaptation to daily stressful events. Neuron 69 (2), 359-372 (2011).

94 Elliott E, Ezra-Nevo G, Regev L, Neufeld-Cohen A, Chen A. Resilience to social stress coincides with functional DNA methylation of the $C r f$ gene in adult mice. Nat. Neurosci. 13(11), 1351-1353 (2010).

95 Kember RL, Dempster EL, Lee TH, Schalkwyk LC, Mill J, Fernandes C. Maternal separation is associated with strainspecific responses to stress and epigenetic alterations to $\mathrm{Nr} 3 \mathrm{cl}$, Avp, and Nr4a1 in mouse. Brain Behav. 2(4), 455-467 (2012).

96 Sterrenburg L, Gaszner B, Boerrigter J et al. Chronic stress induces sex-specific alterations in methylation and expression of corticotropin-releasing factor gene in the rat. PLoS ONE 6(11), e28128 (2011)

97 Weaver IC, Cervoni N, Champagne FA et al. Epigenetic programming by maternal behavior. Nat. Neurosci. 7(8), 847-854 (2004).
98 Uddin M, Aiello AE, Wildman DE et al. Epigenetic and immune function profiles associated with post-traumatic stress disorder. Proc. Natl Acad. Sci. USA 107(20), 9470-9475 (2010).

- Reports on the first epigenome-wide association study of PTSD, where blood DNA methylation of more than 14,000 genes was measured from 100 individuals. The top genes identified highlight the essential role of the immune system in PTSD.

99 Smith AK, Conneely KN, Kilaru V et al. Differential immune system DNA methylation and cytokine regulation in post-traumatic stress disorder. Am. J. Med. Genet. B Neuropsychiatr. Genet. 156b(6), 700-708 (2011).

100 Von Kanel R, Hepp U, Kraemer B et al. Evidence for low-grade systemic proinflammatory activity in patients with post-traumatic stress disorder. J. Psychiatr. Res. 41(9), 744-752 (2007).

101 Mehta D, Klengel T, Conneely KN et al. Childhood maltreatment is associated with distinct genomic and epigenetic profiles in post-raumatic stress disorder. Proc. Natl Acad. Sci. USA 110(20), 8302-8307 (2013).

- Determined that individuals with PTSD have distinct DNA methylation patterns depending on whether or not they had been exposed to childhood abuse, highlighting the long-lasting effects of early-life trauma on the methylome.

102 Turecki G, Meaney MJ. Effects of the social environment and stress on glucocorticoid receptor gene methylation: a systematic review. Biol. Psychiatry 79(2), 87-96 (2016).

103 Sadeh N, Spielberg JM, Logue MW et al. SKA2 methylation is associated with decreased prefrontal cortical thickness and greater PTSD severity among trauma-exposed veterans. Mol. Psychiatry 21(3), 357-363 (2015).

104 Morris MC, Compas BE, Garber J. Relations among posttraumatic stress disorder, comorbid major depression, and HPA function: a systematic review and meta-analysis. Clin. Psychol. Rev. 32(4), 301-315 (2012).

105 Roth TL, Zoladz PR, Sweatt JD, Diamond DM. Epigenetic modification of hippocampal Bdnf DNA in adult rats in an animal model of post-traumatic stress disorder. J. Psychiatr. Res. 45(7), 919-926 (2011).

106 Keller S, Sarchiapone M, Zarrilli F et al. Increased BDNF promoter methylation in the Wernicke area of suicide subjects. Arch. Gen. Psychiatry 67(3), 258-267 (2010).

107 Rusiecki JA, Byrne C, Galdzicki Z et al. PTSD and DNA methylation in select immune function gene promoter regions: a repeated measures case-control study of U.S. military service members. Front. Psychiatry 4, 56 (2013).

108 Boks MP, Van Mierlo HC, Rutten BP et al. Longitudinal changes of telomere length and epigenetic age related to traumatic stress and post-traumatic stress disorder. Psychoneuroendocrinology 51, 506-512 (2015).

109 Horvath S. DNA methylation age of human tissues and cell types. Genome Biol. 14(10), R115 (2013).

110 Yehuda R, Daskalakis NP, Desarnaud F et al. Epigenetic biomarkers as predictors and correlates of symptom improvement following psychotherapy in combat veterans with PTSD. Front. Psychiatry 4, 118 (2013). 
111 Sipahi L, Wildman DE, Aiello AE et al. Longitudinal epigenetic variation of DNA methyltransferase genes is associated with vulnerability to post-traumatic stress disorder. Psychol. Med. 44(15), 3165-3179 (2014).

112 Gluckman PD, Hanson MA, Cooper C, Thornburg KL. Effect of in utero and early-life conditions on adult health and disease. N. Engl. J. Med. 359(1), 61-73 (2008).

113 Kessler RC, McLaughlin KA, Green JG et al. Childhood adversities and adult psychopathology in the WHO World Mental Health Surveys. Br. J. Psychiatry. 197(5), 378-385 (2010).

114 McGowan PO, Sasaki A, D’Alessio AC et al. Epigenetic regulation of the glucocorticoid receptor in human brain associates with childhood abuse. Nat. Neurosci. 12(3), 342-348 (2009).

-• A seminal study which established that severe childhood abuse results in increased hippocampal NR3C1 methylation in humans.

115 Labonte B, Suderman M, Maussion G et al. Genome-wide epigenetic regulation by early-life trauma. Arch. Gen. Psychiatry 69 (7), 722-731 (2012).

116 Levenson JM, Sweatt JD. Epigenetic mechanisms in memory formation. Nat. Rev. Neurosci. 6(2), 108-118 (2005).

117 Oberlander TF, Weinberg J, Papsdorf M, Grunau R, Misri S, Devlin AM. Prenatal exposure to maternal depression, neonatal methylation of human glucocorticoid receptor gene (NR3C1) and infant cortisol stress responses. Epigenetics 3(2), 97-106 (2008).

118 Palma-Gudiel H, Cordova-Palomera A, Eixarch E, Deuschle M, Fananas L. Maternal psychosocial stress during pregnancy alters the epigenetic signature of the glucocorticoid receptor gene promoter in their offspring: a meta-analysis. Epigenetics 10(10), 893-902 (2015).

119 Mansell T, Vuillermin P, Ponsonby AL, Collier F, Saffery R, Ryan J. Maternal mental well-being during pregnancy and glucocorticoid receptor gene promoter methylation in the neonate. Dev. Psychopathol. doi: 10.1017/ S0954579416000183 1-10 (2016) (Epub ahead of print).

120 Devlin AM, Brain U, Austin J, Oberlander TF. Prenatal exposure to maternal depressed mood and the MTHFR C677T variant affect SLC6A4 methylation in infants at birth. PLoS ONE 5(8), e12201 (2010).

121 Thaler L, Gauvin L, Joober R et al. Methylation of BDNF in women with bulimic eating syndromes: associations with childhood abuse and borderline personality disorder. Prog. Neuropsychopharmacol. Biol. Psychiatry 54, 43-49 (2014).

122 Mansell T, Novakovic B, Meyer B et al. The effects of maternal anxiety during pregnancy on IGF2/H19 methylation in cord blood. Transl. Psychiatry 6, e765 (2016).
123 Naumova OY, Lee M, Koposov R, Szyf M, Dozier M, Grigorenko EL. Differential patterns of whole-genome DNA methylation in institutionalized children and children raised by their biological parents. Dev. Psychopathol. 24(1), 143-155 (2012).

124 Essex MJ, Boyce WT, Hertzman C et al. Epigenetic vestiges of early developmental adversity: childhood stress exposure and DNA methylation in adolescence. Child Dev. 84(1), 58-75 (2013).

125 Yang BZ, Zhang H, Ge W et al. Child abuse and epigenetic mechanisms of disease risk. Am. J. Prev. Med. 44(2), 101-107 (2013).

126 Houtepen LC, Vinkers CH, Carrillo-Roa T et al. Genomewide DNA methylation levels and altered cortisol stress reactivity following childhood trauma in humans. Nat. Commun. 7, 10967 (2016).

-• An important study which demonstrates that stress reactivity in humans is epigenetically regulated. They found that the KIT ligand gene was differentially methylated in association with cortisol stress reactivity, it mediated the association between childhood trauma and cortisol levels, and methylation levels in blood were correlated with those in the prefrontal cortex.

127 Varricchio L, Tirelli V, Masselli E et al. The expression of the glucocorticoid receptor in human erythroblasts is uniquely regulated by KIT ligand: implications for stress erythropoiesis. Stem Cells Dev. 21(15), 2852-2865 (2012).

128 Zannas AS, Arloth J, Carrillo-Roa T et al. Lifetime stress accelerates epigenetic aging in an urban, African-American cohort: relevance of glucocorticoid signaling. Genome Biol. 16, 266 (2015).

129 Van Der Knaap LJ, Riese H, Hudziak JJ et al. Glucocorticoid receptor gene (NR3C1) methylation following stressful events between birth and adolescence. The TRAILS study. Transl. Psychiatry 4, e381 (2014).

130 Yehuda R, Daskalakis NP, Bierer LM et al. Holocaust exposure induced intergenerational effects on FKBP5 methylation. Biol. Psychiatry 80(5), 372-380 (2015).

131 Cichon S, Craddock N, Daly M et al. Genomewide association studies: history, rationale, and prospects for psychiatric disorders. Am. J. Psychiatry 166(5), 540-556 (2009).

132 Logue MW, Amstadter AB, Baker DG et al. The psychiatric genomics consortium post-traumatic stress disorder workgroup: post-traumatic stress disorder enters the age of large-scale genomic collaboration. Neuropsychopharmacology 40 (10), 2287-2297 (2015).

133 Abel T, Zukin RS. Epigenetic targets of HDAC inhibition in neurodegenerative and psychiatric disorders. Curr. Opin. Pharmacol. 8(1), 57-64 (2008). 